\title{
The Toxin Cercosporin is a Virulence Factor for Infection of Coffee by Cercospora
}

\section{coffeicola}

\author{
A. G. C. Souza ${ }^{1}$, S. Herrero ${ }^{1,2}$, and M. E. Daub ${ }^{*}$ \\ ${ }^{1}$ Department of Plant and Microbial Biology, North Carolina State University, Raleigh, NC \\ 27695-7612, USA \\ ${ }^{2}$ Current address: Syngenta, 9 Davis Dr., Durham, NC 27709, USA \\ *Corresponding author, margaret_daub@ncsu.edu.
}

\begin{abstract}
Brown eye spot, caused by Cercospora coffeicola, causes significant losses in both quality and quantity of coffee production. As many Cercospora spp. produce the photoactivated toxin cercosporin, this study aimed to determine the role of cercosporin in C. coffeicola pathogenesis by creating disruption mutants unable to produce the toxin. Six C. coffeicola isolates from Brazilian fields, representing organic and conventional production systems in the Minas Gerais state, were evaluated for their ability to produce cercosporin in vitro. Toxin production varied among isolates, ranging from $3.5-25.3 \mu \mathrm{M} / 5 \mathrm{~mm}$ mycelial plug; production was undetectable in one isolate. The C. coffeicola homolog of the polyketide synthase gene (CTB1) involved in cercosporin production was amplified using a degenerate primer strategy. The $7044 \mathrm{nt}$ cCCTB1 gene sequence was $90.3 \%$ identical to the CnCTB1 gene in Cercospora nicotianae and encoded a putative protein of 2196 amino acids with $98.2 \%$ similarity and $97.5 \%$ identity to its counterpart in C. nicotianae. Transformation of two isolates of $C$. coffeicola with a CTB1 disruption construct resulted in the recovery of six $c t b 1$ disruption mutants. All of the $c t b 1$ disruptants were deficient in cercosporin production. Disruption mutants did not differ significantly from the wild type for either growth or sporulation, but were significantly altered in virulence on coffee. As compared to wild type,
\end{abstract}


time to lesion development was significantly increased and numbers of lesions were significantly decreased in coffee plants inoculated with ctb1 disruption mutants. These results show that cercosporin toxin is a virulence factor for C. coffeicola infection of coffee.

Keywords: Coffee; brown eye spot; Cercospora coffeicola; cercosporin; plant disease; fungal pathogenesis; cercosporin-deficient mutant

\section{INTRODUCTION}

Brazil is the major world producer of coffee. An important coffee disease is brown eye spot, caused by Cercospora coffeicola, which causes losses in both quality and quantity of production (36). Although the importance of the disease is well known, there are no cultivars resistant to the pathogen, and disease control relies primarily on fungicide sprays. The infection process of C. coffeicola on the coffee leaf has been studied (29), but little else is known about $C$. coffeicola pathogenesis mechanisms.

Plant pathogenic fungi use many strategies to cause disesase. One common strategy involves the production of toxins that kill host cells, allowing for tissue colonization by the pathogen (2, 25). Many Cercospora species produce cercosporin (23), a perylenequinone toxin. Cercosporin is light-activated, generating reactive oxygen species (ROS) such as singlet oxygen and superoxide $(12,14)$. The production of toxic ROS makes cercosporin almost universally toxic, with toxicity documented to host and non-host plants, bacteria, many fungi, and even mice (13). In host plants, cercosporin secreted by the fungus accumulates in membranes, leading to peroxidation of membrane lipids and death of the host cells, allowing for tissue colonization by the fungus $(11,14)$. The biosynthetic pathway for cercosporin production has been elucidated in $C$. nicotianae $(4,5,6,7,16)$. The gene cluster contains genes encoding a polyketide synthase (CTB1; $\underline{\text { Cercosporin }}$ Toxin $\underline{B}$ iosynthesis 1$)$, two $O$ - 
methyltransferases (CTB2, CTB3), three oxidoreductases (CTB5, CTB6, CTB7), an MFS transporter (CTB4), and a transcriptional activator (CTB8). Genes involved in cercosporin production not found in the gene cluster have also been characterized in several species. These include $C F P$ ( $\underline{\text { Cercosporin }}$ Facilitator Protein, encoding an MFS transporter) in $C$. kikuchii and C. beticola $(3,15)$ and C. nicotianae (31); CRG1 (ㅌercosporin Resistance Gene, encoding a zinc cluster transcription factor) in C. nicotianae $(8,10)$; ATR1 (encoding an ABC Transporter) in C. nicotianae $(1,21)$; and CZK3 (encoding a MAP kinase) in C. zeae-maydis (26). Non-cercosporin-producing mutants of C. nicotianae and C. beticola, disrupted for genes in the biosynthetic pathway, produced fewer lesions as compared to the wild-type when these mutants were inoculated onto tobacco and sugar beet leaves, demonstrating that cercosporin is an important virulence factor in disease development on some hosts $(4,7,16$, 30, 33). By contrast, cercosporin is not produced by strains of Cercospora arachidicola, and there is no evidence that cercosporin plays a role in disease on peanut (18).

There are no reports on the genes involved in cercosporin production by C. coffeicola. It has been shown that shading reduces fungal penetration, and fewer lesions develop on shaded leaves (17). In previous studies (28), we found high variability in cercosporin production by isolates of C. coffeicola collected in different locations in the Minas Gerais state of Brazil. We also found a positive correlation between cercosporin production in vitro and virulence (28). These studies suggested that cercosporin can be an important virulence factor for C. coffeicola infection on coffee, and that efforts to identify genes involved in cercosporin resistance may allow for novel strategies for developing coffee with resistance to brown eye spot, by targeting toxin production or resistance.

The goal of this work was to determine the role of the cercosporin toxin in virulence of C. coffeicola by creating cercosporin-deficient mutants and investigating changes in disease development. Here we report the identification and sequence of a C. coffeicola homolog of 
CTB1 (cCCTB1) encoding the cercosporin polyketide synthase (PKS), the recovery and characterization of cercosporin-deficient mutants by disruption of $c C$ CTB1, and virulence of these mutants on coffee. Our results document an important role for cercosporin in virulence of C. coffeicola on coffee.

\section{MATERIALS AND METHODS}

Isolates. Six isolates of C. coffeicola differing in production of cercosporin and virulence were recovered from three Minas Gerais regions (Mata [M], Sul de Minas [S], and Triângulo $[\mathrm{T}]$ ) and from two cropping systems (conventional $[\mathrm{C}]$ and organic $[\mathrm{O}]$ ). The six isolates used were: WT-MO53, WT-SO40, WT-SC31, WT-MC56, WT-TO02, WT-TC07 (WT = wild type; $\mathrm{M}, \mathrm{S}, \mathrm{T}=$ regions; $\mathrm{C}, \mathrm{O}=$ crop systems; numbers are random). The isolates were routinely cultured on "complete medium" agar or potato dextrose agar (PDA) at $25^{\circ} \mathrm{C}$ in either lighted (for cercosporin production) or dark growth chambers as described (1). All analysis of variance and means comparisons were performed with $\mathrm{SAS}^{\circledR}$ v. 9.1. The assay to evaluate the ability of the $c t b 1$ mutants to infect the coffee plants in vivo was conducted at the Universidade Federal de Viçosa. All other experiments were conducted at North Carolina State University.

Cercospora coffeicola DNA isolation. Mycelial cultures from either wildtype or $c t b 1$ mutants were grown as previously described (9), and genomic DNA was isolated from lyophilized mycelium using the Fungal DNA Miniprep kit (Omega Bio-Tek, Norcross, GA, USA) following the manufacturer's recommendations.

Amplification of a polyketide synthase (ccCTB1) from Cercospora coffeicola. The $C$. coffeicola CTB1 gene (ccCTB1) was amplified by PCR from an isolate showing high levels of 
cercosporin and virulence (WT-SO40), using first, cnCTB1-specific primers derived from conserved regions of the C. nicotianae CTB1 sequence (GenBank accession number AAT69682.1), including degenerate primers derived from highly conserved polyketide synthase sequences (Ketosyntase [KS] and Acyl Transferase [AT] domains), and second, cCCTB1-specific primers derived from sequence information generated above. Sequence information on non-coding 5'- and 3'- end flanking regions of cCCTB1 was also generated. PCR was performed in a $50 \mu \mathrm{lmix}$ using Apex ${ }^{\circledR}$ Taq Polymerase (Genesee Scientific, San Diego, CA, USA) following standard procedures. The PCR products were sent to Eton Bioscience, Inc. (Research Triangle Park, NC) for sequencing, and gene sequences were assembled using the sequence analysis software Vector NTI v.10 (Invitrogen, Carlsbad, CA).

CTB1 gene disruption. The isolates WT-SO40 and WT-SC31, showing the highest cercosporin production and high virulence, were selected for disruption of $c C C T B 1$. A splitmarker disruption strategy similar to the one described previously described $(1,6,34)$ was used to create $c C C T B 1$-disrupted isolates. The disruption vector pCTB115 containing a hygromycin-resistance gene $(H Y G)$ flanked by cnCTB1 sequences from C. nicotianae was used for replacement of the cCCTB1 homolog in C. coffeicola. Two different overlapping PCR fragments were amplified from pCTB115 and were used as part of the split-marker strategy to disrupt cCCTB1. A 2.6-kb fragment containing the 5'-end sequences of cnCTB1 and another 2.4-kb fragment containing 3'-end sequences of cnCTB1 were amplified as previously described (6). Protoplasts were generated and transformed as previously described $(19,20,27)$. The transformed cultures were selected on regeneration medium containing 125 $\mu \mathrm{g} / \mathrm{ml}$ of hygromycin as described (1). The transformants were screened initially for lack of cercosporin production in culture according to the methodology described below. C. coffeicola transformants that did not produce cercosporin were verified by PCR to confirm 
successful disruption. Primers 3R (5'-CTCCAAGAACGTTTCGCTGT-3') and OUTF (5'CCATCTCATCTGCACTTCCGTTCTT-3') were used to amplify a fragment of ccCTB1 gene specific only to the intact WT sequence. The 3R primer was designed to hybridize inside of the $c C C T B 1$ region (position of the $3240 \mathrm{nt}$ ) putatively disrupted by the disruptioncassette, whereas the OUTF primer hybridized at the 5' upstream region (-200 nt). The second set of primers OUTF and Hyg3 (5'GGATGCCTCCGCTCGAAGTA3') were used to amplify a region spanning the disruption construct to confirm gene disruption the $C C C T B 1$ gene by the HYG gene.

Cercosporin production assay. To assay for cercosporin production, the transformants and the wild type were grown on PDA at $25^{\circ} \mathrm{C}$ under $12 \mathrm{~h}$ of light, conditions that induce cercosporin production in the wild type. The production was visually identified as a red pigment on the under-side of colonies 4-5 days after plating. Cercosporin production was quantified by extracting mycelial plugs in $5 \mathrm{~N} \mathrm{KOH}$ as described (6). The amount of cercosporin in the extract was quantified spectrophotometrically by measuring absorbance at 480, 590 and $640 \mathrm{~nm}(35)$. The wild type isolate used to generate the mutants as well as the other C. coffeicola isolates (WT-MO53, WT-MC56, WT-TO02, and WT-TC07) were used as controls. The experiment was conducted twice, each time in a randomized complete block design with three replicates (one tube $=$ one experimental unit).

Growth and conidia production. Growth of $C$. coffeicola wild type and ccctb1 mutant isolates was measured on PDA with and without hygromycin $(125 \mu \mathrm{g} / \mathrm{ml})$ by measuring the colony diameter every 3 days for 12 days. The technique of drying the mycelial mass was used to induce conidial production (29). Briefly, mycelial plugs were grown with shaking in $10 \mathrm{ml}$ liquid V8 medium (20\% V8) at $120 \mathrm{rpm}, 25^{\circ} \mathrm{C}, 12 \mathrm{~h}$ light. After 4 days, the cultures 
were transferred to open Petri dishes under fluorescent lamps, at $25^{\circ} \mathrm{C}$ and with a $12-\mathrm{h}$ photoperiod. After dehydration of the culture medium (approximately 4 days), $10 \mathrm{ml}$ of distilled water were added to each Petri dish, the fungal colony was scratched with a glass rod, and the suspension was filtered through one layer of cheesecloth. The conidial concentration was evaluated with a haemocytometer. Each experiment was conducted twice, each time in a randomized complete design with three replicates (one plate $=$ one experimental unit). Each experiment was analyzed separately.

Pathogenicity of $\boldsymbol{c t b} 1$ disruptants on coffee. Inoculation experiments utilized two ccctb1disrupted isolates generated from the WT-SC31 (MUT7 and MUT12), one transformant that was not disrupted (MUT13), and the WT-SC31. Plants of 'Catuaí Vermelho IAC44' ('Catuaí') at six months after sowing with two pairs of leaves were used for the inoculation experiments. The plants were grown in plastic bags $(10 \times 20 \mathrm{~cm})$ containing a mixture of soil, sand, and cow manure in a proportion of 3:1:1 (v:v:v). The inoculum suspension was adjusted to $4.5 \times 10^{4}$ conidia/mL and sprayed on both sides of four leaves per plant using a DeVilbiss sprayer. Distilled water was sprayed on the control plants. For the first $12 \mathrm{~h}$ after inoculation, the plants were set in a wet chamber, which was kept at $25^{\circ} \mathrm{C}$ with $90 \pm 5 \%$ relative humidity $(\mathrm{RH})$, and continuous light (40 W grow lux lamps distributed alternately to provide light intensity of $165.3 \mu \mathrm{mol} / \mathrm{s} / \mathrm{m}^{2}$ ). Subsequently, the plants were transferred to a greenhouse with natural daylight and without temperature control.

Each plant was assessed at five-day intervals from the $10^{\text {th }}$ to the $50^{\text {th }}$ day after inoculation. The evaluations measured the incubation period (IP, defined as the the number of days between inoculation and the appearance of the first symptom on a leaf), as well as lesion number and disease severity at the $35^{\text {th }}$ and $50^{\text {th }}$ day after inoculation. For each plant, the IP, lesion number and severity were calculated by averaging the values of the four 
inoculated leaves. The disease severity was evaluated based on a diagrammatic scale (24) with five grades: $1(0 \%) ; 2$ ( $>0$ to $3 \%$ ); 3 (>3 to $6 \%$ ); 4 (>6 to $12 \%$ ); and 5 (>12 to $25 \%$ ) diseased area. The intermediate severity value between the lower and the upper limits of each grade was used in the statistical analysis. The contrast procedure $(\alpha=0.01)$ of $\operatorname{SAS}^{\circledR}$ v. 9.1 was used to compare the mean of IP, number of lesions and severity at the $35^{\text {th }}$ and $50^{\text {th }}$ day after inoculation. The experiment was conducted twice, each time in a randomized complete design with seven replicates (one plant with four leaves= one experimental unit). Each experiment was analyzed separately.

\section{RESULTS}

Cercosporin production by wild type isolates. Cercosporin production of C. coffeicola wild type (WT) cultures was quantified from mycelium grown on PDA. Cercosporin production values were significantly different from each other according the Tukey test $(\alpha=0.05)$. Isolates WT-SO40 and WTSC31 had the highest values, 25.17 and $16.50 \mu \mathrm{M} / 0.5 \mathrm{~cm}$ mycelial plug, respectively. Isolates WT-TC07, WT-ZO53, and WT-TC02 produced 9.3, 7.5, and 4.0 $\mu \mathrm{M} / 0.5 \mathrm{~cm}$ mycelial plug, respectively; production was undetectable in isolate WT-ZC56. The WT isolates with highest levels of the cercosporin production (WT-SO40 and WTSC31) were selected for disruption of the $c C C T B 1$ gene.

\section{Amplification of a cercosporin polyketide synthase gene from C. coffeicola (ccCTB1).}

The full-length sequence of $c C$ CTB1 was determined as described in Materials and Methods by sequencing multiple overlapping PCR fragments amplified from WT-SO40 (highest cercosporin production and virulence). The size of the ccCTB1 (GenBank accession number HQ173811.1) from C. coffeicola is $7044 \mathrm{nt}$, and it is $90.3 \%$ identical to cnCTB1 from C. nicotianae. The size of the ccCTB1 protein in C. coffeicola is 2196 aa, and it is $98.2 \%$ similar 
and $97.5 \%$ identical to its counterpart in C. nicotianae. Similar to C. nicotianae, the cCCTB1 gene contains a total of eight small introns. The $c C C T B 1$ introns ranged from 47 to $80 \mathrm{bp}$ in size and are distributed throughout the gene as follows: Intron 1: 294-344; Intron 2: 649-706; Intron 3:1488-1534; Intron 4: 1687-1743; Intron 5: 1793-1839; Intron 6: 4504-4583; Intron 7: 4940-5000; and Intron 8: 6314-6368. Alignment analysis of CTB1 sequences of C. nicotianae (GenBank accession number AY649543) and C. coffeicola (GenBank accession number HQ173811.1) showed a high level of conserved amino acids between these proteins, with identity and similarity values of 97 and $93 \%$, respectively.

ccCTB1 gene disruption and evaluation of cercosporin production. The C. coffeicola cCCTB1 gene showed high homology to $\mathrm{cnCTB1}$ in C. nicotianae. Thus the vector pCTB115 used to disrupt CTB1 from C. nicotianae (6) was used for disruption of the cCCTB1 gene in C. coffeicola using a split marker approach. The two wild type isolates with the highest levels of cercosporin production, WT-SO40 and WT-SC31, were selected for ccCTB1 disruption. Transformants were selected for hygromycin (HYG) resistance. HYG-resistant isolates were then screened for lack of visible red pigmentation (cercosporin) when grown on PDA. To ensure that transformants did not contain a mix of disrupted and wild type nuclei, isolates were transfered six times on PDA amended with $125 \mu \mathrm{g} / \mathrm{ml}$ of hygromycin before quantifying cercosporin production and confirming disruption by PCR.

Cercosporin production was assayed by extraction in $\mathrm{KOH}$ and quantification by absorption spectroscopy. Cercosporin is readily detectable by a green-color when extracted in 5N KOH (Fig. 1), and absorption spectroscopy showed the presence of typical peaks at 480, 590 and $640 \lambda$ that were not observed in isolates that failed to produce cercosporin (data not shown). Out of 126 HYG-resistant transformants obtained for both isolates, nine (4/111 transformants of WT-SO40; 5/15 transformants of WT-SC31) did not have detectable levels 
of cercosporin as assayed by $\mathrm{KOH}$ extraction (Fig. 1). Cercosporin production by one randomly selected cercosporin-producing transformant from each parent (MUT5 from WTSO40 and MUT13 from WT-SC31) was quantified and shown to be similar to their wild type parents; WT-SO40 and MUT 5 produced 43.5 and $40.5 \mu \mathrm{M} / 0.5 \mathrm{~cm}$ mycelial plug, respectively, and WT-SC31 and MUT13 produced 26.5 and $24.3 \mu \mathrm{M} / 0.5 \mathrm{~cm}$ mycelial plug, respectively.

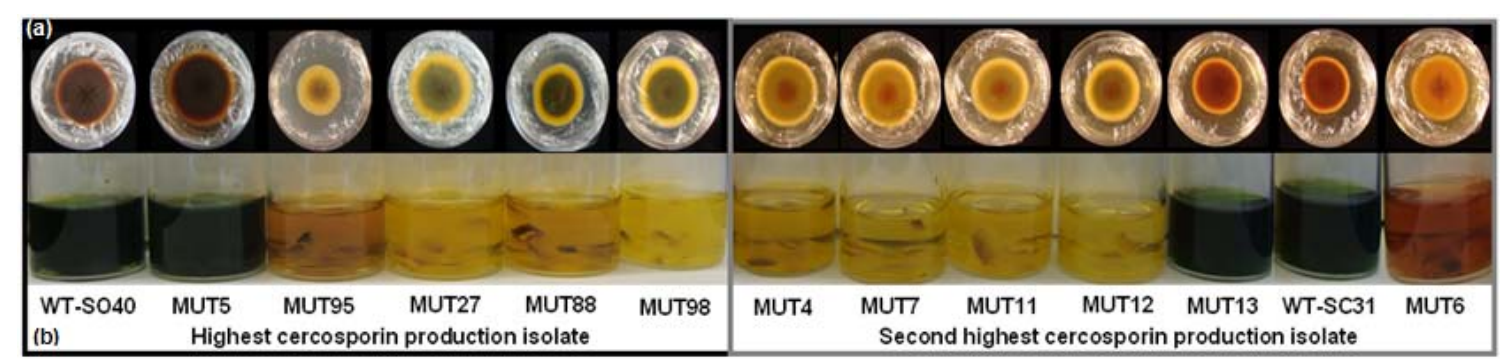

Figure 1. Cercosporin production by wild type (WT) C. coffeicola isolates and transformants (MUT) following transformation with the $c t b 1$ disruption construct. Transformants were recovered from transformation of the two highest cercosporin-producing wild type isolates: WT-SO40 (MUT5, MUT95, MUT27, MUT88, and MUT98) and WT-SC31 (MUT7, MUT11, MUT12, MUT13, and MUT6). (a) Colonies grown in PDA with HYG (12 days, $25^{\circ} \mathrm{C}, 12 \mathrm{~h}$ light). Red pigmentation indicates certosporin production. (b) Extraction of cercosporin from mycelial plugs using 5N KOH. Dark green extract indicates presence of cercosporin. WTSO40, WT-SC31 and two transformants, MUT5 and MUT13, produced cercosporin whereas all remaining transformants (MUT95, MUT27, MUT88, MUT98, MUT4, MUT7, MUT11, MUT12, MUT6) did not produce cercosporin.

Confirmation of ccctb1 disruption by PCR. The nine non-cercosporin-producing transformants and two selected cercosporin-producing transformants were analyzed by PCR to confirm targeted disruption of $c c C B T 1$ gene of C. coffeicola. Primers 3R (in the ccCTB1 ORF) and OUTF (upstream of coding sequence) were used to amplify a fragment of ccCTB1 gene specific only to the intact WT sequence. The second set of primers (OUTF and Hyg3) was used to amplify a region spanning the disruption construct to a genomic region outside 
the construct to confirm homologous integration and gene disruption the $C C C T B 1$ gene by the HYG gene. Of the wild type parent strains, nine transformants lacking cercosporin production, and two cercosporin-producing transformants analyzed, only the two wild type strains showed the presence of the intact $c C C T B 1$ gene (Fig. 2). Six of the nine cercosporindeficient transformants (MUT4, MUT7, MUT12, MUT88, MUT95 and MUT98) were confirmed to lack the intact $c C$ CTB1 gene and also contain the expected band confirming cCCTB1 disruption. In addition, three cercosporin-deficient transformants (MUT6, MUT11 and MUT27) and two cercosporin-producing transformants (MUT5, MUT13) lacked a detectable wild type copy; however, the disruption of cCCTB1 could not be confirmed for these isolates. These results may indicate rearrangements during the integration process.

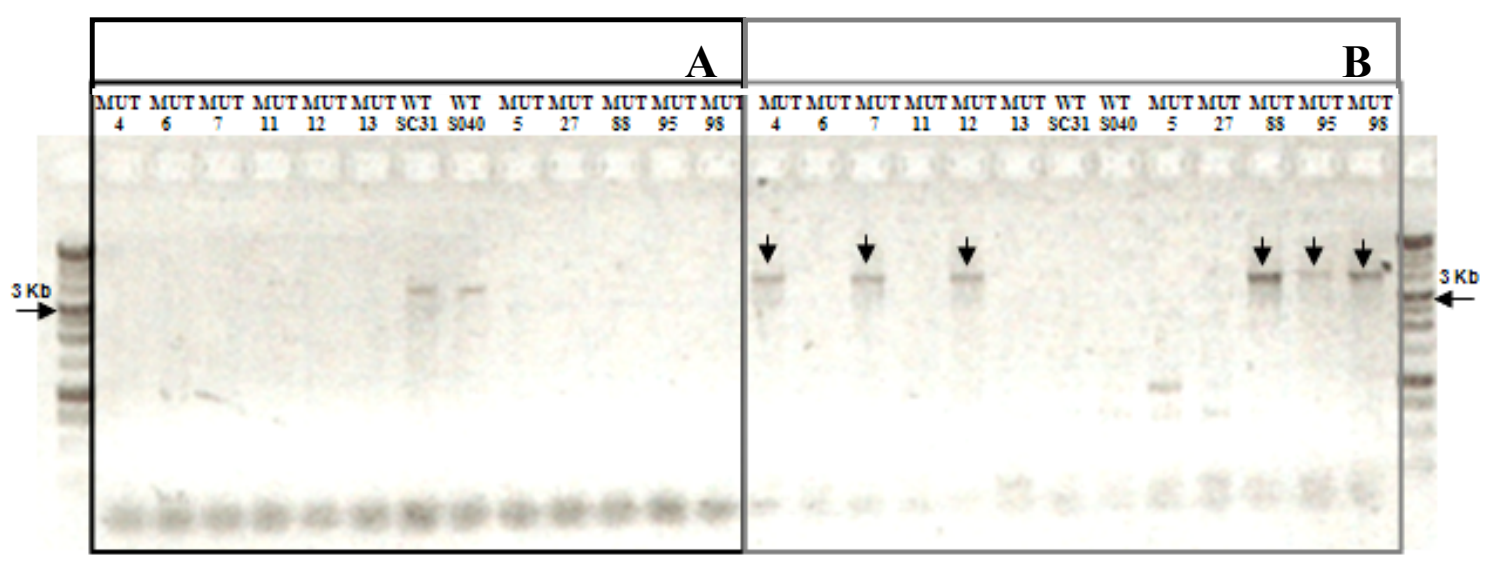

Figure 2. Molecular analysis of C. coffeicola wild type (WT) and transformants transformed with the $c t b 1$ disruption construct (MUT). Protoplasts were transformed as described in Materials and Methods. Regenerated colonies were selected for HYG resistance, and screened for lack of cercosporin production. Two sets of primers, OUTF and 3R [A] or OUTF and Hyg3 [B], were used to identify, respectively, the WT $(3.5 \mathrm{~Kb})$ or disrupted $(4.0 \mathrm{~Kb})$ copies of the $c C C T B 1$ gene in isolates. Panel A shows amplification of the WT gene in SC31 and SO40. Amplified bands in panel B indicate presence of the disrupted gene. Arrows indicate disrupted mutants. MUT5, MUT27, MUT88, MUT95 and MUT98 isolates came from WT-SO40; MUT4, MUT6, MUT7, MUT11, MUT12 and MUT13 isolates came from WT-SC31. 
Growth and conidia production of ccctb1 disrupted isolates. Wild type, the six confirmed ccctb1-disrupted transformants, and selected non-disrupted transformants were analyzed for growth rate in culture and conidial production. As expected, neither of the wild type isolates (WT-SO40 and WT-SC31) grew on PDA supplemented with hygromycin. There were no significant differences in growth on PDA medium between the wild type isolates and any of the transformants, either the ccctb1 disruptants or the non-disrupted transformants (Table 1).

TABLE 1. Average radial growth (diameter in $\mathrm{cm}$ ) after 12 days of wild type parent isolates (WT), ccctb1-disrupted transformants $\left({ }^{* *}\right)$, and non-disrupted transformants $\left({ }^{\mathrm{x}}\right)$ grown on potato dextrose agar (PDA) and PDA supplemented with hygromycin (PDA+HYG), in two different experiments

\begin{tabular}{|c|c|c|c|c|c|}
\hline \multirow{2}{*}{$\begin{array}{l}\text { Wild Type } \\
\text { Parent }\end{array}$} & \multirow{2}{*}{ Isolate } & \multicolumn{2}{|c|}{ First experiment } & \multicolumn{2}{|c|}{ Second experiment } \\
\hline & & PDA* $^{*}$ & PDA+HYG* & PDA* & $\mathrm{PDA}+\mathrm{HYG}^{*}$ \\
\hline \multirow[t]{6}{*}{ WT-SO40 } & WT-SO40 & $1.11 \mathrm{~A}$ & $0.00 \mathrm{~B}$ & $1.80 \mathrm{~A}$ & $0.00 \mathrm{~B}$ \\
\hline & MUT5 $^{\mathrm{x}}$ & $1.14 \mathrm{~A}$ & $1.23 \mathrm{~A}$ & $1.91 \mathrm{~A}$ & $2.00 \mathrm{~A}$ \\
\hline & MUT95** & $1.26 \mathrm{~A}$ & $0.95 \mathrm{~A}$ & $1.92 \mathrm{~A}$ & $1.30 \mathrm{~A}$ \\
\hline & MUT88** & $1.47 \mathrm{~A}$ & $1.18 \mathrm{~A}$ & $2.00 \mathrm{~A}$ & $1.80 \mathrm{~A}$ \\
\hline & MUT98** & $1.59 \mathrm{~A}$ & $1.43 \mathrm{~A}$ & $2.35 \mathrm{~A}$ & $2.03 \mathrm{~A}$ \\
\hline & $\operatorname{MUT2} 7^{x}$ & $1.64 \mathrm{~A}$ & $1.31 \mathrm{~A}$ & $2.22 \mathrm{~A}$ & $2.11 \mathrm{~A}$ \\
\hline \multirow[t]{7}{*}{ WT-SC31 } & WT-SC31 & $1.28 \mathrm{~A}$ & $0.00 \mathrm{~B}$ & $1.79 \mathrm{~A}$ & $0.00 \mathrm{~B}$ \\
\hline & MUT13 $^{x}$ & $1.35 \mathrm{~A}$ & $1.22 \mathrm{~A}$ & $1.84 \mathrm{~A}$ & $1.98 \mathrm{~A}$ \\
\hline & MUT6 $^{\mathrm{x}}$ & $1.44 \mathrm{~A}$ & $1.36 \mathrm{~A}$ & $2.19 \mathrm{~A}$ & $2.13 \mathrm{~A}$ \\
\hline & MUT7** & $1.52 \mathrm{~A}$ & $1.40 \mathrm{~A}$ & $2.09 \mathrm{~A}$ & $2.09 \mathrm{~A}$ \\
\hline & MUT4** & $1.53 \mathrm{~A}$ & $1.44 \mathrm{~A}$ & $2.10 \mathrm{~A}$ & $2.22 \mathrm{~A}$ \\
\hline & MUT11 ${ }^{\mathrm{x}}$ & $1.55 \mathrm{~A}$ & $1.54 \mathrm{~A}$ & $2.28 \mathrm{~A}$ & $2.23 \mathrm{~A}$ \\
\hline & MUT12** & $1.55 \mathrm{~A}$ & $1.51 \mathrm{~A}$ & $2.20 \mathrm{~A}$ & $2.22 \mathrm{~A}$ \\
\hline
\end{tabular}

*Values with different letters in the same column of a wild type isolate indicate significantly different growth (Tukey's test, $\alpha=0.05$ ). 
For sporulation, differences were found in numbers of spores produced between isolates in both experiments $(\mathrm{P}<0.0001)$. However, there was no consistent difference between the wild type parents and the ccctb1 disruptants across both experiments (Table 2).

TABLE 2. Average sporulation (conidia/ml) of wild type (WT), ctb1-disrupted-transformants $\left({ }^{* *}\right)$, and non-disrupted transformants $\left(^{\mathrm{x}}\right)$ in two experiments

\begin{tabular}{|c|c|c|c|}
\hline \multicolumn{4}{|l|}{ Wild Type } \\
\hline Parent & Isolate & First experiment* & Second experiment* \\
\hline \multirow[t]{6}{*}{ WT-SO40 } & WT-SO40 & $262500 \mathrm{AB}$ & $145000 \mathrm{~A}$ \\
\hline & MUT5 $^{\mathrm{x}}$ & $232500 \mathrm{AB}$ & $185000 \mathrm{~A}$ \\
\hline & $\operatorname{MUT27x}$ & $215000 \mathrm{~B}$ & $215000 \mathrm{~A}$ \\
\hline & MUT95** & $27500 \mathrm{C}$ & $145000 \mathrm{~A}$ \\
\hline & MUT88** & $18000 \mathrm{C}$ & $125000 \mathrm{~A}$ \\
\hline & MUT98** & $13000 \mathrm{C}$ & $175000 \mathrm{~A}$ \\
\hline \multirow[t]{7}{*}{ WT-SC31 } & MUT12** & $292500 \mathrm{~A}$ & $170000 \mathrm{C}$ \\
\hline & MUT7** & $282500 \mathrm{AB}$ & $217500 \mathrm{C}$ \\
\hline & MUT6 $^{\mathrm{x}}$ & $225000 \mathrm{ABC}$ & $342500 \mathrm{~B}$ \\
\hline & MUT13 & $185000 \mathrm{C}$ & $292500 \mathrm{BC}$ \\
\hline & MUT11 & $165000 \mathrm{C}$ & $485000 \mathrm{~A}$ \\
\hline & WT-SC31 & $16750 \mathrm{D}$ & $362500 \mathrm{~B}$ \\
\hline & MUT4** & $14250 \mathrm{D}$ & $402500 \mathrm{AB}$ \\
\hline
\end{tabular}

Pathogenicity of ccctb1 disruptants on coffee. To determine the importance of cercosporin in C. coffeicola pathogeneis on coffee, WT-SC31, two independent ccctb1 disrupted mutants from WT-SC31 (MUT7, MUT12), and a non-disrupted, cercosporin-producing transformant from WT-SC31 (MUT13) were inoculated onto coffee. Incubation period (IP), lesion numbers, and disease severity ratings were determined. In both experiments, medium values 
of the IP and SEV35 and SEV50 (disease severity at the $35^{\text {th }}$ and $50^{\text {th }}$ day after inoculation) were not stastically different between the cercosporin-producing wild type WT-SC31 and the non-disrupted cercosporin-producing MUT13 transformant (Table 3), showing that the transformation procedure did not affect virulence. Differences were seen between the two cercosporin-producing strains (WT-SC31 and the non-disrupted MUT13) and the disrupted strains (MUT7, MUT12) that do not produce cercosporin. The incubation periods (IP) associated with the cercosporin-producer isolates (WT-SC31 and MUT13) were statistically different $(\mathrm{P}<0.01)$ from the non-cercosporin producers (MUT7 and MUT12) in both experiments. The average values of the IP of the two cercosporin-producing isolates (WTSC31 and MUT13) were 30.3 and 32.3 days whereas IP for the two disrupted non-producing mutants (MUT7 and MUT12) were 38.3 and 41.3 days on the first and second experiments, respectively (Table 3). The averages of the number of lesions (NL) produced on leaves were also significantly different between cercosporin-producing and non-producing isolates. NL associated with the cercosporin-producing isolates was significantly higher $(\mathrm{P}<0.01)$ than for the non-producers at the $35^{\text {th }}$ and $50^{\text {th }}$ days after inoculation in both experiments (Table 3 ). Variation in severity values was high, limiting statistical significance. 
TABLE 3. Number of lesions (NL), severity (SEV), and incubation period (IP) of brown eye spot on coffee leaves caused by Cercospora coffeicola isolates. Leaves were inoculated with wild type (WT-SC31), a cercosporin-producing non-disrupted transformant (MUT13), and two ccctb1 disupted mutants (MUT7, MUT12) unable to produce cercosporin. NL and SEV were evaluated at 35 (NL35, SEV35) and 50 (NL50, SEV50) days after inoculation. Each value is the mean of three replications per experiment in two independent experiments (E1 and E2).

\begin{tabular}{llllllllllll}
\hline \multirow{2}{*}{ Isolate } & \multirow{2}{*}{ Cerc $^{1}$} & \multicolumn{2}{c}{ NL35 } & \multicolumn{2}{c}{ NL50 } & \multicolumn{2}{c}{ SEV35 } & \multicolumn{2}{c}{ SEV50 } & \multicolumn{2}{c}{ IP } \\
\cline { 3 - 11 } & & E1 & E2 & E1 & E2 & E1 & E2 & E1 & E2 & E1 & E2 \\
\hline WT-SC31 & + & 4.29 & 1.78 & 10.29 & 3.03 & 0.95 & 0.86 & 1.45 & 1.12 & 31.43 & 30.30 \\
MUT13 & + & 6.00 & 0.63 & 7.29 & 0.82 & 1.38 & 0.53 & 1.39 & 0.70 & 29.17 & 34.29 \\
MUT7 & - & 1.61 & 0.21 & 3.95 & 0.37 & 0.43 & 0.63 & 1.18 & 0.75 & 39.29 & 43.18 \\
MUT12 & - & 1.32 & 0.56 & 3.79 & 0.82 & 0.79 & 0.25 & 1.02 & 0.37 & 37.32 & 39.34 \\
\hline Cerc+ $\times$ Cer-* & 0.0012 & 0.0002 & 0.0030 & 0.0003 & 0.0148 & 0.062 & 0.13 & 0.0188 & 0.0083 & 0.0002 \\
\hline
\end{tabular}

${ }^{1}$ Cercosporin production

*Significance (P-values) of a statistical contrast that tested whether cercosporin producer isolates (Cerc + ) were different from non-producer isolates (Cerc-) regarding each variable in each experiment.

\section{DISCUSSION}

Many species of plant pathogenic fungi produce toxins that act as virulence factors and help parasitize their hosts $(2,25)$. Many Cercospora spp. produce the light-activated photosensitizing toxin cercosporin $(14,23)$. Mutants of C. nicotianae, C. kikuchii, and C. zeae-maydis have been generated to confirm the role of cercosporin as a virulence factor $(3,6$, 26). Our epidemiological studies suggested that cercosporin is involved in virulence of $C$. coffeicola on coffee, as we found a positive correlation between cercosporin production and virulence (28). To conclusively show the relatedness between cercosporin production and virulence of C. coffeicola, we isolated a C. coffeicola polyketide synthase gene homologous to 
the $\underline{\text { Cercosporin }}$ Toxin $\underline{B} i o s y n t h e s i s$ gene 1 (CTB1) in C. nicotianae. We then determined cCCTB1's role in fungal cercosporin biosynthesis by generating isolates lacking this gene.

In our study, sequence analysis of ccCTB1 in C. coffeicola revealed strong similarity to the cnCTB1 protein involved in cercosporin production by C. nicotianae. The ccCTB1 sequence was also similar to other polyketide synthase (PKS) sequences of other fungi, including the ALB1 protein involved in conidial pigment biosynthesis in Penicillium marneffei and Aspergillus fumigates with 65\% (accession number XM002147681) and 67\% (accession number XM751002) identity, respectively. As with the C. nicotianae CTB1, the C. coffeicola CTB1 contains five catalytic domains: a keto synthase (KS), an acyltransferase (AT), a thioesterase (TE), and two acyl carrier protein (ACP) domains, involved in the initial steps of cercosporin synthesis (6). Other genes, including CTB3 (encoding a dual methyltransferase/monooxygenase), CTB4 (encoding a putative membrane transporter), CZK3 (gene that regulates cercosporin biosynthesis, fungal development, and pathogenesis), and CFP (encoding a membrane transport protein required for secretion of cercosporin), are also involved with cercosporin production, confirming that cercosporin biosynthesis is a process that involves multiple genes and signals $(3,6,7,16,26)$.

We conducted gene disruption experiments and were successful in isolating disrupted transformants for the $c C C T B 1$ gene that do not produce cercosporin. Analysis of cercosporin production by transformants showed a direct correlation between cercosporin production and disruption of $c C C T B 1$; transformants confirmed by PCR as disruption mutants did not produce cercosporin. These results confirm that the $c C C T B 1$ gene is required for cercosporin biosynthesis in C. coffeicola. These results provide the first report of a gene involved in the cercosporin biosynthesis pathway in C. coffeicola.

The cercosporin-non producing ccctb1 disruption mutants were evaluated for other traits important in disease development including growth and sporulation. In our study, 
disruption of $c C C T B 1$ did not affect growth in vitro. A similar result was reported when ctb4and $c t b 3$-disrupted isolates of $C$. nicotianae were compared; disrupted isolates produced less cercosporin although they had a similar growth as the wild type $(7,16)$. Similarly, disruption of the CFP gene of C. kikuchii led a loss of $95 \%$ of the cercosporin production as compared to the wild type isolate with no change in growth (32). C. kikuchii UV-generated mutants unable to produce cercosporin grew more than the wild type on solid medium, although the growth on liquid medium did not differ (32). In C. zeae-maydis, disruption isolates for the CZK3 gene that are defective in cercosporin production had higher vegetative growth than the wild type (26). Overall growth differences do not appear to correlate with production or lack of production of cercosporin, and may be due to the specific genes defective in these mutants.

Cercospora spp. sporulate profusely on the lesions to generate secondary inoculum that accounts for biological fitness and survival. There are reports of non-cercosporin producing C. kikuchii and C. zeae-maydis isolates having reduced sporulation $(3,26,32)$. However, in other studies $C$. nicotianae $c t b 1$ and $c t b 3$ mutants unable to produce cercosporin sporulated similarly to the wild type isolate $(6,16)$. We did not find a significant difference in sporulation between cercosporin-producing and non-producing isolates of C. coffeicola. Considering the relevance of sporulation on disease progress on the field, it would be interesting to quantify both cercosporin production and sporulation on the host tissue to verify if there is any relation between them.

The role of the cercosporin production in the ability of Cercospora spp. to parasitize plants has been studied for different pathosystems $(3,4,6,16,26)$. In our study, we found that the cercosporin-producing isolates produced more lesions as compared to the nonproducing disruptants when these isolates were inoculated onto coffee leaves. In addition, incubation period was also significantly longer for the non-cercosporin producing disruptants. As secondary cycles are important in the epidemics of policyclic diseases, such as brown eye 
spot, changes in incubation period would alter the course of epidemics. Our results are similar to studies in other systems where mutants of $C$. nicotianae unable to synthesize cercosporin were shown to produce fewer lesions as compared to the wild type when these mutants were inoculated onto tobacco leaves $(4,16)$. In our study, numbers of lesions could distinguish the virulence of cercosporin-producing from the non-producing isolates. However, disease severity measurements did not always correlate with cercosporin production. Severity was visually estimated, thus errors and variability can be larger than lesion numbers and obscure any statistical difference. The use of diagrammatic scales is an effective method to evaluate the disease severity, but the occurrence of visual errors is frequently observed with the use of this technique (22). It is also possible that cercosporin can be more important for C. coffeicola infection (thus, the difference in the number of lesions) than for the colonization of leaves (thus, the partial differences in the severity values). Our results confirm our epidemiological and correlative data on the importance of cercosporin in C. coffeicola pahtogenicity (28). Our study also demonstrates there are additional mechanisms and genes that are involved in C. coffeicola pathogenicity because mutants that were unable to produce cercosporin were able to parasitize the coffee leaf and produce lesions.

In summary, we isolated and characterized a polyketide synthase gene from $C$. coffeicola responsible for production of cercosporin. Using gene-disruption technology, we created disrupted mutants unable to produce cercosporin. Analysis of disease development on coffee showed that the mutants produced fewer lesions with a longer incubation period. Both of these factors will strongly influence the progress and spread of the disease in the field, underscoring the importance of cercosporin in brown eye spot. This is the first report where molecular genetic manipulation of C. coffeicola has been used to define a critical pathogenicity factor. In addition to confirming the long-held hypothesis of the importance of 
cercosporin in brown eye spot, the results from this study provide fundamental information needed to address the development of novel disease control strategies. Possible control strategies include the development of fungicides that block the cercosporin synthesis, engineering coffee to silence cercosporin synthesis, or engineering or breeding coffee for toxin resistance. Knowledge gained from this work advances our understanding of $C$. coffeicola and its interactions with coffee plants, and may provide practical uses for our knowledge to better control brown eye spot.

\section{ACKNOWLEDGMENTS}

We thank Dr. Luis Maffia, Departamento de Fitopatologia, Universidade Federal de Viçosa, Viçosa, MG 36570000, Brazil, for support and assistance with the inoculation experiments. Support for this research was provided by $\mathrm{CNPq} / \mathrm{NCSU} / \mathrm{UFV}$ and FAPEMIG. 


\section{LITERATURE CITED}

1. Amnuaykanjanasin, A., and Daub, M. E. 2009. The ABC transporter ATR1 is necessary for efflux of the toxin cercosporin in the fungus Cercospora nicotianae. Fungal Genet. Biol. 46:146-158.

2. Berestetskiy, A. O. 2008. A review of fungal phytotoxins: from basic studies to practical use. Appl. Biochem. Microbiol. 44:453-465.

3. Callahan, T., Rose, M., Meade, M., Ehrenshaft, M., and Upchurch, R. 1999. CFP, the putative cercosporin transporter of Cercospora kikuchii, is required for wild type cercosporin production, resistance, and virulence on soybean. Mol. Plant Microbe Interact. 12:901-910. 4. Chen, H. Q., Lee, M. H., and Chung, K. R. 2007. Functional characterization of three genes encoding putative oxidoreductases required for cercosporin toxin biosynthesis in the fungus Cercospora nicotianae. Microbiology 153:2781-2790.

5. Chen, H., Lee, M. H., Daub, M. E., and Chung, K. R. 2007. Molecular analysis of the cercosporin biosynthetic gene cluster in Cercospora nicotianae. Mol. Microbiol. 64:755-770.

6. Choquer, M., Dekkers, K. L., Chen, H.-Q., Cao, L., Ueng, P. P., Daub, M. E., and Chung, K. R. 2005. The CTB1 gene encoding a fungal polyketide synthase is required for cercosporin toxin biosynthesis and fungal virulence in Cercospora nicotianae. Mol. Plant Microbe Interact. 18:468-476.

7. Choquer, M., Lee, M. H., Bau, H. J., and Chung, K. R. 2007. Deletion of a MFS transporter-like gene in Cercospora nicotianae reduces cercosporin toxin accumulation and fungal virulence. FEBS letters 581:489-494.

8. Chung, K. R., Jenns, A. E., Ehrenshaft, M., and Daub, M. E. 1999. A novel gene required for cercosporin toxin resistance in the fungus Cercospora nicotianae. Mol. Genet. Genomics 262:382-389. 
9. Chung, K. R., Ehrenshaft, M., and Daub, M. E. 2002. Functional expression and cellular localization of cercosporin-resistance proteins fused with the GFP in Cercospora nicotianae. Curr. Genet. 41:159-167.

10. Chung, K. R., Daub, M. E., Kuchler, K., and Schüller, C. 2003. The CRG1 gene required for resistance to the singlet oxygen-generating cercosporin toxin in Cercospora nicotianae encodes a putative fungal transcription factor. Biochem. Biophys. Res. Commun. $302: 302-310$.

11. Daub, M. E. 1982. Peroxidation of tobacco membrane lipids by the photosensitizing toxin, cercosporin. Plant Physiol. 69:1361-1364.

12. Daub, M. E., and Hangarter, R. P. 1983. Light-induced production of singlet oxygen and superoxide by the fungal toxin, cercosporin. Plant Physiol. 73:855-857.

13. Daub, M. E., Herrero, S., and Chung, K. R. 2005. Photoactivated perylenequinone toxins in fungal pathogenesis of plants. FEMS Microbiol. Lett. 252:197-206.

14. Daub, M. E., Herrero, S., and Chung, K. R. 2013. Reactive oxygen species in plant pathogenesis: the role of perylenequinone photosensitizers. Antiox. Redox Signal. 9:970-989. 15. de Jonge, R., Ebert, M. K., Huitt-Roehl, C.R., Pal, P., Suttle, J.C., Spanner, R.E., Spanner, R. E., Neubauer, J. D., Jurick, W. M. II, Stott, K. A., Secor, G. A., Thomma, B. P. H. J, Van de Peer, Y., Townsend, C. A., Bolton, M. D. 2018. Gene cluster conservation provides insight into cercosporin biosynthesis and extends production to the genus Colletotrichum. Proc Natl Acad Sci. 115:E5459-E5466, https://doi.org/10.1073/pnas.1712798115. 16. Dekkers, K. L., You, B. J., Gowda, V. S.; Liao, H. L., Lee, M. H., Bau, H. J., Ueng, P. P., and Chung, K. R. 2007. The Cercospora nicotianae gene encoding dual O-methyltransferase and FAD-dependent monooxygenase domains mediates cercosporin toxin biosynthesis.

Fungal Genet. Biol. 44:444-454. 
17. Echandi, E. 1959. La chasparria de los cafetos causada por el hongo Cercospora coffeicola Berk and Cooke. Turrialba 9:54-67.

18. Fore, S. A., Daub, M. E., and Beute, M. K. 1988. Phytotoxic substances produced by certain isolates of Cercospora arachidicola are not cercosporin. Phytopathology 78:10821086.

19. Gwinn, K. D., and Daub, M. E. 1988. Regenerating protoplasts from Cercospora and Neurospora differ in their response to cercosporin. Phytopathology 78:414-418.

20. Gwinn, K. D., and Daub, M. E. 1989. Techniques for isolation of mutants using protoplasts from Cercospora nicotianae. Mycologia 81:322-324.

21. Herrero, S., Amnuaykanjanasin, A., and Daub, M. E. 2007. Identification of genes differentially expressed in the phytopathogenic fungus Cercospora nicotianae between cercosporin toxin-resistant and -susceptible isolates. FEMS Microbiol. Lett. 275:326-337. 22. Madden, L.V., Hughes, G., Van Der Bosch, F. 2007. The study of plant disease epidemics. American Phytopathological Society, St. Paul, MN. 421 pp.

23. Okubo, A., Yamazaki, S., and Fuwa, K. 1975. Biosynthesis of cercosporin. Agr. Biol. Chem. 39:1173-1175.

24. Oliveira, C. A., Pozza, E. A., Oliveira, V. B., Santos, R. C., and Chaves, Z. M. 2001.

Escala diagramática para avaliação da severidade de cercosporiose em folhas de cafeeiro. In: Embrapa café (ed) II Simpósio Brasileiro de Pesquisa dos Cafés do Brasil, 24-27 September 2001. Vitória, ES, Brazil, pp 1151-1157.

25. Scheffer, R. P. 1991. Role of toxins in evolution and ecology of plant pathogenic fungi. Experientia 47:804-811.

26. Shim, W. B., and Dunkle, L. D. 2003. CZK3, a MAP kinase kinase kinase homolog in Cercospora zeae-maydis, regulates cercosporin biosynthesis, fungal development, and pathogenesis. Mol. Plant. Microbe In. 16:760-768. 
27. Souza, A. G. C., Herrero, S., Maffia, L. A., Daub, M. E. 2014. Methods for Cercospora coffeicola protoplast isolation and genetic transformation with the Green Fluorescent Protein. Eur. J. Plant Pathol. 139:235-238.

28. Souza, A. G. C., Maffia, L. A., and Mizubuti, E. S. G. 2012. Cultural and aggressiveness variability of Cercospora coffeicola. J. Phytopath. 160:540-546.

29. Souza, A. G. C., Rodrigues, F. A., Maffia, L. A., and Mizubuti, E. S. G. 2011. Infection process of Cercospora coffeicola on coffee leaf. J. Phytopath. 159:6-11.

30. Staerkel, C., Boenisch, M. J., Kröger, C., Bormann, J., Schäfer, W., and Stahl, D. 2013. $\mathrm{CbCTB} 2$, an O-methyltransferase is essential for biosynthesis of the phytotoxin cercosporin and infection of sugar beet by Cercospora beticola. BMC Plant Biol. 13:50.

31. Upchurch, R. G., Rose, M. S., Eweida, M., and Zuo, W. 2005. Expression of the cercosporin transporter, CFP, in tobacco reduces frog-eye lesion size. Biotechnol. Lett. $27: 1543-1550$.

32. Upchurch, R. G., Walker, D. C., Rollins, J. A., Ehrenshaft, M., and Daub, M. E. 1991. Mutants of Cercospora kikuchii altered in cercosporin synthesis and pathogenicity. Appl. Environ. Microbiol. 57:2940-2945.

33. Weiland, J. J., Chung, K. R., and Suttle, J. C. 2010. The role of cercosporin in the virulence of Cercospora spp. to plant hosts. pp. 109 - 117 in: R. T. Lartey, J. J. Weiland, L. Panella, P. W. Crous, and C. E. Windels, ed. Cercospora leaf spot of sugar beet and related species. APS Press, St. Paul, MN.

34. You, B. J., Lee, M. H., and Chung, K. R. 2009. Gene-specific disruption in the filamentous fungus Cercospora nicotianae using a split-marker approach. Arch. Microbiol. $191: 615-622$. 
35. You, B. J., Lee, M. H., and Chung, K. R. 2008. Production of cercosporin toxin by the phytopathogenic Cercospora fungi is affected by diverse environmental signals. Can. J.

Microbiol. 54:259-269.

36. Zambolim, L., Vale, F. X. R., Pereira, A. A., and Chaves, G. M. 1997. Café (Coffea

arabica). In: Vale, F. X. R., and Zambolim, L., eds. Controle de doenças de plantas: grandes culturas. Viçosa: UFV, pp.83-180. 